\title{
Una cuestión cuatrocentista sobre el valor y la experiencia: estudio y edición*
}

\author{
A $15^{\text {th }}$ century "cuestión" on courage and experience: \\ study and critical edition
}

\author{
José Julio Martín Romero \\ Universidad de Jaén \\ jjmartin@ujaen.es \\ ORCID iD: https://orcid.org/0000-0001-9568-3470
}

\begin{abstract}
RESUMEN: Este artículo ofrece la primera edición crítica y estudio exhaustivo de un texto cuatrocentista de Fernán Mexía. Se trata de una cuestión que su autor dedica a don Álvaro de Mendoza, un importante noble, en la que defiende que solo por medio de la experiencia adquirida a lo largo del tiempo un guerrero puede aumentar su coraje, y rechaza que quien no conoce la guerra pueda ser más valiente (por mucho que ignoren los riesgos y peligros de la vida militar). El autor defiende esta idea en tanto que intenta probar que únicamente aquel que pertenece a un antiguo linaje noble puede ser considerado verdaderamente noble, lo que había defendido en su tratado Nobiliario vero.
\end{abstract}

Palabras clave: nobleza, literatura del siglo XV, Fernán Mexía, caballería.

ABSTRACT: This article offers the first critical edition and thorough study of a $15^{\text {th }}$ century text by Fernán Mexía. This text is a "cuestión" its author dedicates to Álvaro de Mendoza, an important nobleman. In this text Mexía states that only by experience and time a warrior can acquire courage, and rejects that those who never have been in war are braver (even though they ignore the risk and dangers of the military life). This writer defends this idea as he tries to prove that only those belonging to an old noble lineage can be considered real noblemen, what he expressed and defended in his treaty Nobiliario vero.

Keywords: nobility, $15^{\text {th }}$ century literature, Fernán Mexía, chivalry.

\footnotetext{
* Este trabajo se inscribe en el marco del Proyecto I+D+i del MINECO "DHuMAR Humanidades Digitales, Edad Media y Renacimiento. 1. Poesía 2. Traducción” (FFI2013-44286-P). 
El giennense Fernán Mexía es sobre todo conocido por su Nobiliario vero, el tratado sobre nobleza y caballería más ambicioso de los escritos en el cuatrocientos castellano. La fortuna del Nobiliario ha oscurecido el resto de la producción de este autor, no solo sus composiciones poéticas, recogidas en el Cancionero de Juan Álvarez Gato y en el Cancionero General de Hernando del Castillo (Morales Borrero 1997: 83-170), sino también otro texto al que la crítica apenas ha dedicado atención. Me refiero a una curiosa cuestión que el giennense dirige a don Álvaro de Mendoza, conde de Castro y señor de las villas de Gormaz y Astudillo. Se trata de una de esas reflexiones surgidas en el entorno nobiliario y cortesano de esa centuria, que intentaban dilucidar determinados aspectos a partir de la erudición y el razonamiento.

Remitir "cuestiones" o preguntas (en ocasiones son denominadas "demandas") a un determinado personaje se revela como una práctica común en el cuatrocientos castellano. Esa práctica también se descubre en el ámbito poético, si bien en esos casos suele tratarse de juegos de ingenio más que de una búsqueda de la verdad. Así sucede, por ejemplo, en las conocidas cuestiones poéticas entre Juan de Mena y el Marqués de Santillana (2003: 585-634), por ejemplo, o en las que han sido estudiadas por Chas (2000) dedicadas al amor. En este sentido, hay que recordar el intercambio poético de tono moral entre Álvarez Gato y Mexía (Morales Borrero, 1997: 145-147). Pero, además de esos juegos poéticos - orientados la mayor parte de las veces a demostrar el propio ingenio-, también hay numerosos casos de cuestiones no lúdicas sobre un tema en concreto. Muchas de ellas se desarrollaban por medio de cartas, como la Qüistión entre dos cavalleros, en la que se menciona explícitamente este intercambio epistolar: "esto vos a dado a creer que yo vos pueda en algo satisfazer, rrespondiendo a la qüistión que me enbiastes este otro día" (Weiss, 1992: 10); otro caso conocido es la Questión del marqués de Santillana a don Alfonso de Cartagena, que, como Gómez Moreno (1985) comenta, se estableció cuando el primero escribió el 15 de enero de 1444 una carta al segundo para consultarle diversas dudas sobre la caballería que le habían surgido tras leer a Leonardo Bruni.

Por tanto, se trata de una práctica habitual en esos años en los que la aristocracia estaba intentando construir un determinado orden social. Este tipo de cuestiones revela mucho de las inquietudes no solo intelectuales sino también sociales de su momento histórico; su estudio arroja luz sobre la forma como se entendían determinados aspectos fundamentales para comprender el pensamiento de la época, pues, en definitiva, muestran, como afirma Weiss, "el empeño con que la aristocracia iba redefiniéndose según las nuevas pautas sociales" (1992: 9). Temas como el linaje, la nobleza, la caballería, el honor, la mejor forma de servir al bien público, la erudición y la administración resultan casi obsesivos en la tratadística (y no solo en ella) de esa época; ello es debido a que eran las inquietudes sociales en unos años en los que está cambiando el 
orden político. Eran asuntos sobre los que se debatía en los círculos aristocráticos. Un testimonio de debates orales sobre esos temas lo encontramos en el Espejo de verdadera nobleza de Diego de Valera, que confiesa: "acordávame yo muchas vezes aver oído, no solamente en vuestra magnífica casa e corte, mas aun en otras de muy altos reyes e illustres príncipes y grandes barones, de la nobleza o fidalguía trabtar" (Valera, 1959a: 89). Aquí Valera recuerda su pasado viajero y caballeresco que (es consciente de ello) le confiere mayor autoridad en esos asuntos. Me interesa aquí señalar que esto demuestra que esos temas eran frecuentemente objeto de debate, un debate que se realizaba tanto de forma oral (como revela el testimonio de Valera) como epistolar (el caso de la cuestión que aquí edito) ${ }^{1}$.

Esta cuestión de Mexía se conserva en dos manuscritos custodiados actualmente en la Biblioteca Universitaria de Salamanca, BUS 2414 y BUS 2428. Se trata de dos de los tres manuscritos - el otro es el ms. 3311 de la Biblioteca Nacional de España - en los que ha pervivido el Nobiliario vero ${ }^{2}$. Pues bien, justamente al final de los dos manuscritos salmantinos se copia la cuestión a la que dedico el presente estudio.

Esta cuestión pretende determinar quién temerá más los peligros, aquel que ha pasado por ellos o aquel que aún no los conoce; en definitiva, le interesa dilucidar si aquel que no ha combatido en su vida resultará más medroso que aquel que es un guerrero experimentado. Por tanto, se trata de nuevo de una reflexión en torno a la nobleza, pues no hay que olvidar que esta se caracteriza por su función bélica, en la que virtudes como el valor resultan imprescindibles. En este sentido, se trata de una cuestión relacionada con la caballería, entendida como grupo social dedicado a la guerra. Esto vincula claramente esta cuestión con los temas que trata en su Nobiliario vero ${ }^{3}$ y determina su opinión al respecto.

\footnotetext{
${ }^{1}$ También los debates sobre determinados aspectos que podríamos considerar de protocolo caballeresco se vinculan con estas preocupaciones sobre la nobleza (estamento identificado con el de los defensores o caballeros); un testimonio de este tipo de debates lo encontramos en el Tratado de las armas de Diego de Valera: "Cerca de lo qual fue assaz devate conmigo en la corte del señor Duque Felipe de Borgoña, que hoy es, porque truxe ende mi enpresa cubierta (...); el qual debate fue determinado por el dicho señor duque con consejo de los barones cavalleros de su corte" (Valera, 1959b: 129).

2 Además de estos tres manuscritos, esta obra se conserva en numerosos ejemplares de un incunable impreso en 1492 por Pedro Brun y Juan Gentil en Sevilla. No obstante, los manuscritos y el impreso representan estadios de redacción distintos, el último de los cuales, el definitivo, es el del impreso. Sobre los diversos estadios redaccionales de esta obra, Martín Romero (2017).

${ }^{3}$ Este tratado parte del debate suscitado por las ideas de Bartolo de Sassoferrato; las tesis del italiano habían sido defendidas por autores como Diego de Valera, pero también fueron fuertemente rechazadas por otros, encabezados por Juan Rodríguez del Padrón. En este debate, Mexía se sitúa claramente en la línea de este último (Rodríguez Velasco, 1996; Morales Borrero, 1997; Heusch, 2009; Gómez Redondo, 2012: 475-585; y Martín Romero, 2012a y 2014).
} 
Retóricamente delega la decisión última al dedicatario, el citado don Álvaro de Mendoza: "vuestra merced avrá logar de setençiar en la potestad de tam penetrante y discreto saber tan maduro y tan delgado" (fol. 176r/fol. 168r) ${ }^{4}$. La dedicatoria no es casual: don Álvaro de Méndoza pertenecía a uno de los linajes más importantes de ese momento, cuya cabeza era el Marqués de Santillana. En 1456 había sido escogido por Enrique IV como caudillo de algunos caballeros, pues ya en esos años gozaba de una reputación intachable como guerrero, así lo indica Alfonso de Palencia (1999: 145). Su trayectoria militar está jalonada de diversos éxitos. Tras la farsa de Ávila, formó parte, como todo su linaje, de aquellos que se pusieron del lado de Enrique IV. Posteriormente, en la Guerra Civil castellana luchó en el bando de Isabel y Fernando. Finalmente don Álvaro se convirtió en uno de los hombres de confianza de los Reyes Católicos, debido a sus capacidades bélicas, de las que la historiografía del momento da buena cuenta, basten las alusiones que de él se leen en la crónica de Fernando del Pulgar (2007: I, 168, 171, 191, 208 y 348). Si su hermano, Ruy Díaz de Mendoza, señor de Morón, fue maestresala de la reina Isabel, el mismo don Álvaro ocupará puestos tan importantes como jefe de la flota en plena Guerra de Granada. Por tanto, no es inocente que Mexía dirigiera esta cuestión al importante noble dedicado plenamente a la guerra y, por ello, personificación perfecta de los ideales caballerescos (en definitiva, nobiliarios) que el propio Mexía defendía en su Nobiliario vero ${ }^{5}$.

Como he dicho, Mexía delega la última decisión respecto de la cuestión a este perfecto noble, hombre de armas y de letras (también don Álvaro compuso poemas incluidos en el Cancionero General de Hernando del Castillo), pero lo cierto es que ya desde el inicio indica abiertamente su opinión:

yo confiesso sostener de la segunda y postrimera opinión, acostado a ella por rasón de la pura o mayor verdad, segunt que verdad es otrosí por el actoridad de los gloriossos testigos, la probaçión de los cuales, cuando ál sintiese, $<$ meptiría $>$ [mentiría] de mi propia actoridad, opinión o propósito (fol. 176v/ fol. 168v).

No obstante, Mexía va desgranando las razones alegadas por cada una de las dos posturas, esto es, la de aquellos que defienden que quien no conoce aún los peligros de la guerra será menos temeroso en esos actos, y la de quienes

\footnotetext{
${ }^{4}$ Tal como indico en los criterios de edición, señalo la foliación del ms. BUS2414 en redonda, y la del ms. BUS 2428 en cursiva.

${ }^{5}$ Esta dedicatoria no es la única prueba de la relación que hubo de existir entre Fernán y don Álvaro. El manuscrito del Nobiliario vero conservado en la Biblioteca Nacional de España -ms. 3311 - fue copiado en Astudillo, precisamente una de las villas de don Álvaro, a quien se cita expresamente. Ello indica que este manuscrito fue realizado seguramente a instancias de Mendoza.
} 
sostienen lo contrario (que es la opinión que convence a Mexía). De esta forma, ofrece con toda la claridad posible los argumentos de cada una de las dos posturas. Aunque su decisión resulta explícita desde el principio, procede de forma lógica sin hurtar ninguna de las razones que apoyan aquella que él rechaza. A pesar de lo dicho, a la primera de las opiniones dedica tan sólo un par de páginas, en las que indica las tres razones que alegan quienes proponen que el que no ha pasado por los peligros los temerá menos; es muchísimo menos espacio que el que ocupa la defensa de su propia postura, la contraria, argumentando cinco razones apoyadas tanto en ejemplos como en autoridades diversas.

Por tanto, la objetividad de Mexía es solo aparente, pues resulta manifiesto que expone los argumentos de tal manera que conduzcan al lector a coincidir con la opinión que él defiende. Esto se evidencia no solo en la mencionada diferencia de extensión entre los argumentos de cada parte, sino también en la ausencia de auctoritas en la opinión que él rechaza: aunque es cierto que comenta determinados ejemplos de esa postura, en ellos nunca recurre a fuentes filosóficas que pudieran reforzarlos.

Frente a esto, son numerosos los autores a los que cita para apoyar su propia opinión y que revelan su amplia cultura. Son frecuentes las citas de autores clásicos (Aristóteles, Virgilio); tampoco faltan los humanistas italianos (Dante, Boccaccio), si bien en ocasiones puede haber utilizado traducciones, como la que Enrique de Villena hiciera de la Divina comedia ${ }^{6}$, a juzgar por el hecho de que conocía bien la obra de este autor (así se evidencia en su Nobiliario vero) y el que utilice la traducción de este autor de La Eneida, que se evidencia al comparar los siguientes fragmentos:

\begin{tabular}{l|l|}
\hline \multicolumn{1}{|c|}{ Versión de Villena de la Eneida } & \multicolumn{1}{c|}{ Mexía } \\
$\begin{array}{l}\text { Adelante encontremos los troyanos en el } \\
\text { agua, mientre están temerosos y sallidos } \\
\text { deleznan en las primeras pisadas (Villena, } \\
\text { 2000b: 362). }\end{array}$ & $\begin{array}{l}\text { entremos a los troyanos en el agua mien- } \\
\text { tras están temerosos y salidos delesnan en } \\
\text { las primeras pisadas (fol. 184r/fol. 175v). }\end{array}$ \\
\hline
\end{tabular}

Ese uso de las fuentes por parte de Mexía también se observa cuando cita de forma prácticamente literal (pero con un cierto grado de reelaboración) la Visión deleitable, de Alfonso de la Torre:

${ }^{6}$ En este sentido Mexía es otro ejemplo más de esos primeros ecos del humanismo que analizó Gómez Moreno (1994). Existe edición moderna de la traducción que Villena realizó de la obra de Dante (Villena, 2000a). Los estudios fundamentales para conocer los diversos fenómenos de la traducción en la Edad Media son Alvar (2010) y Alvar y Lucía Megías (2009). 


\section{Visión deleytable}

\section{Mexía}

Los otros son fuertes por costunbres, que los otros son fuertes por costumbres, ca por ventura han seýdo en muchas batallas aviendo seído en muchas batallas a los e se han avido muy bien en ellas, e con cuales ha ido bien, aquella confiança aquella confianza cometen las cosas ar- fázelos ossados (fol. 182v/fol. 174r). duas (Torre, 1991: 303).

Aunque la traducción de Dante realizada por Villena y las citas de Mexía no parecen coincidir de igual manera, la comparación con la versión, seguramente posterior (Hamlin, 2013), de Pedro Fernández de Villegas evidencia las similitudes entre las otras $\operatorname{dos}^{7}$ :

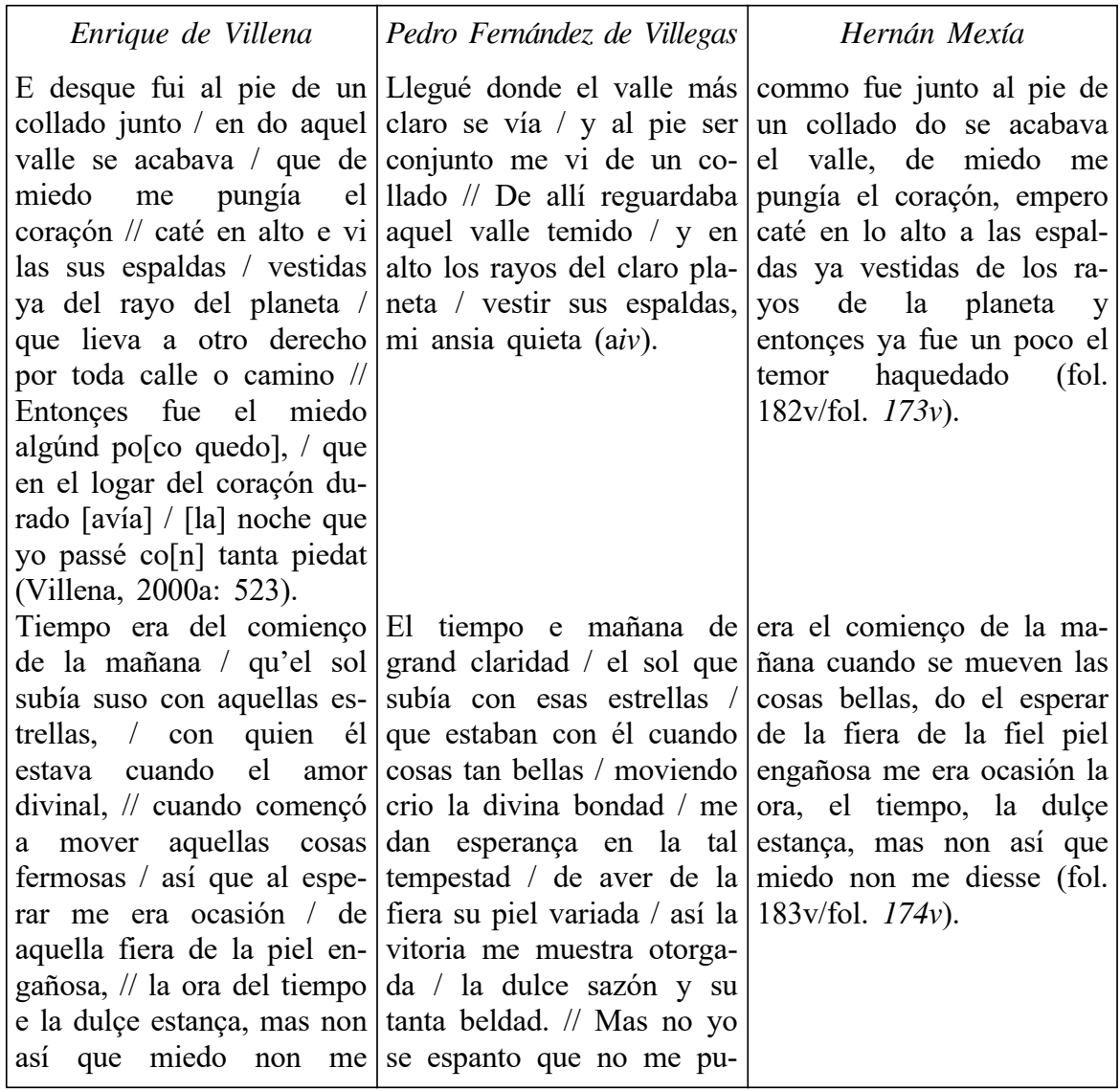

${ }^{7}$ Existe, además de la de Enrique de Villena y de la versión parcial de Pedro Fernández de Villegas, otra (también parcial) realizada por un autor anónimo (Alvar, 2010: 243). 


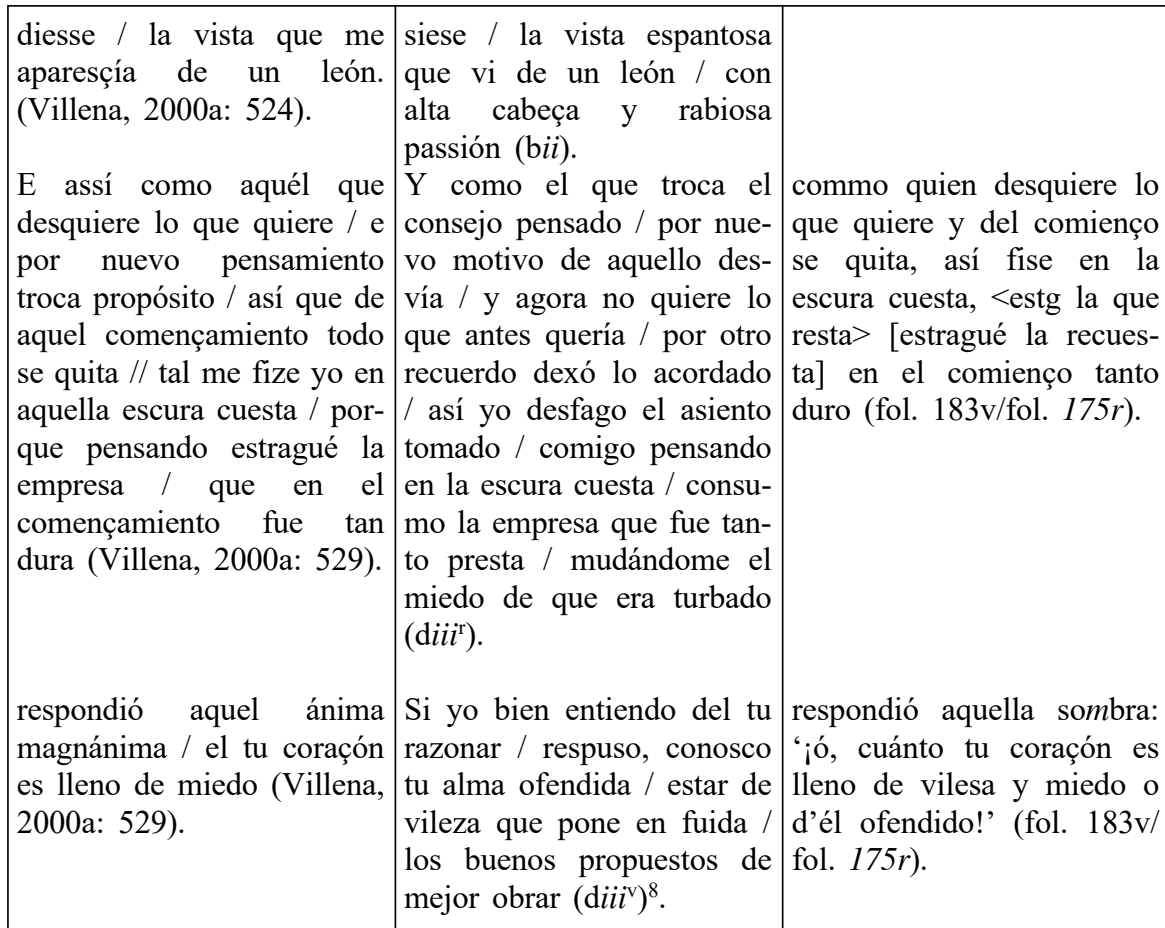

En cualquier caso, ante estas divergencias, se puede plantear que utilizara otra fuente (o manejara más de una) o bien que partiera de notas tomadas en diversos momentos de sus lecturas, no siempre de forma literal, quizá resumiendo o apuntando como un simple recordatorio, o extrayendo aquello que más se adecuaba a sus intereses. En el primer caso, las semejanzas son notables, y parece que se ha limitado a eliminar algunas palabras, pero en los otros se observan diferencias que resultan más difíciles de explicar.

En cuanto a la estructura, Mexía organiza su Cuistión buscando claridad expositiva; como se ha indicado, procede a indicar las razones, esto es, los argumentos, de cada una de las posturas. En primer lugar ofrece aquellos de la primera opinión:

1. Es necesario conocer para temer, solo se teme lo que se conoce, de manera que solo quien conoce los peligros puede temerlos.

${ }^{8}$ Utilizo el ejemplar R/2519 de la Biblioteca Nacional de España de La Tradución del Dante (...) por el reverendo don Pedro Fernández de Villegas, arcediano de Burgos (Fadrique Alemán de Basilea, Burgos, 1515). Utilizo los mismos criterios de edición que para la cuestión de Mexía. Para más información sobre las traducciones de la Eneida en esa época, Alvar (2010: 342). 
2. Se ama la vida: el que conoce los peligros sabe que por ellos puede perder la vida $\mathrm{y}$, por tanto, los teme más.

3. Se ama la salud: el que conoce los peligros sabe que por ellos puede perderla, y, por consiguiente, los teme más.

Los argumentos aportados para defender la postura contraria son cinco y, como se ha indicado, ocupan mucho más espacio:

1. Lo no conocido asusta más, porque se desconocen sus consecuencias; quien ha pasado por esos peligros sabe que puede salir de ellos y, por ello, los teme menos.

2. La práctica lleva a la perfección, por tanto, la práctica de la fortaleza nos conduce a ser más valientes.

3. (No se trata de un argumento, sino de pruebas):

3.1. Las autoridades que así lo afirman.

3.3. Los ejemplos que se observan en la realidad.

4. El "arte" militar — esto es, la técnica y el ejercicio en la guerra - evita el engaño y, por tanto, consigue que disminuya el miedo.

5. Cuanto menos conocimiento, mayor sospecha; la sospecha es el origen del miedo; por lo tanto, la ignorancia es causa de mayor temor.

Estas cinco "razones" conducen a las conclusiones que Mexía quiere defender: "todo aquel el cual por espirençia y prueva á passado y visto muchos peligros temerá menos los peligros, los trabajos, los inconvinientes y daños de las batallas y de las otras cosas" (fol. 183r/fol. 174r). Aunque afirma "de las otras cosas", resulta evidente que su interés se centra en los riesgos y peligros "de las batallas". Entre los ejemplos con los que en sus conclusiones quiere convencer definitivamente al lector, se encuentra el del labrador, que, acostumbrado a su trabajo, sufre mejor el calor y los rayos del sol en verano; continúa con el ejemplo que más le interesa, el de los caballeros, que pueden soportar mejor su vida que la de quienes no están acostumbrados a ella:

otrosí los cavalleros o varones ussados o acostumbrados de traer o comportar el crudo arnés en las guerreras huestes, que non el fijo del mercader, ussado $\mathrm{y}$ acostumbrado estar en la tienda emparamentada y toldada $<\mathrm{s}>$ de ricas sedas y paños finos (fol. 183v/fol. 174r-v).

Se ha de observar que propone una visión de la vida caballeresca mucho más dura que la del burgués. Esa visión parece defender los privilegios de la clase nobiliaria, pues incide en los rigores de su actividad guerrera. En este sentido, se acerca a la visión de la vida militar que expuso Juan de Lucena en De vita felici: 
La cavallería es de gran provecho y mayor ornamento, bien lo veo; mas si tú comparas con el provecho los daños, entonçe cognosçeras cuánt lueñe de feliçidat se remota. ¿Cuál bevir es tan áspero? ¿Cuál más grave o qué cosa es tan intolerable? ¿Quién puede enumerar los peligros de la guerra, desastros y casos de la batalla? (...) Ni come, ni duerme, ni jamás un hora fuelga en reposo, expiando a otros o con miedo de ser insidiado (Lucena, 2004: 545).

La insistencia durante el cuatrocientos en la dureza de la vida del caballero ha de vincularse con los cambios sociales y políticos de esos años. Efectivamente, como es sabido, renace lo cortés y caballeresco porque la nobleza deseaba recuperar una imagen gloriosa de sí misma (Huizinga, 2005 y Riquer, 1967); las ficciones artúricas, la lírica cortés y las historias de caballerías en general reflejaban abiertamente la supremacía del noble y la justificaban por sus virtudes intrínsecas ${ }^{9}$, de ahí que renazcan con fuerza los libros de caballerías, en los que se refleja un concepto de nobleza de linaje y, por tanto, antibartolista (Martín Romero, 2012b). Pero, además de la ficción, son numerosos los tratados que también insisten en las penalidades de la vida del caballero, además de los citados De vita felici de Juan de Lucena y el Nobiliario vero, del mismo Fernán Mexía, añadiré solo otro que, además, coincide con la defensa del ejercicio militar; me refiero a la Perfección del triunfo militar de Alfonso de Palencia (1996), inicialmente escrito en latín pero posteriormente romanzado, tal como hizo con otro tratado suyo vinculado con aspectos bélicos, La batalla campal de los perros contra los lobos (Martín Romero, 2013) ${ }^{10}$. Pues bien, la Perfección del triunfo militar ofrece una reflexión en forma alegórica sobre los aspectos fundamentales y necesarios para alcanzar el éxito en la guerra. Esta alegoría narra cómo el ejercicio, con el nombre de Gloridoneo, viaja a Italia para averiguar por qué, a pesar de las virtudes propias de los españoles, en la actualidad no logran los éxitos esperados en ese terreno. Allí (tras haber pasado también por Francia) entiende la necesidad de otros factores; el orden y la disciplina. Finalmente, tras un debate sobre la primacía de estas virtudes, se decide que son necesarias las tres, que participan en un desfile, cada una en su lugar, montadas en un carro triunfal. Alfonso de Palencia defiende explícitamente la necesidad de ejercicio en esta obra, cuando Gloridoneo, su forma alegórica, afirma:

Cosa muy conosçida es a ty, nin lo pueden dubdar los enseñados oyentes, quánto sea yo neçesario a los guerreros en todas las oras y en todos los momentos. Si conviene caminar, si usar rebates contra los enemigos, o repelirlos si ellos los fizieren; si çercar devidamente de fossado y de barrera,

\footnotetext{
${ }^{9}$ Para una visión de conjunto sobre la leyenda artúrica en España resulta ahora imprescindible Alvar (2015).

${ }^{10}$ Además de las citadas ediciones de estas obras de Palencia, vid. el interesante análisis sobre estas obra en Gómez Redondo (2007: 3761-3782).
} 
velar puertas o mudar guardas o sofrir paçientemente frío, calor, fambre, sed, ¿cúyo ofiçio se requiera? Ya ¿para qué /f3r/ contaré de las escaramuças que se cometen sabiamente, e presto se han de dexar, donde la suma consiste en el pecho fuerte, e en las muy exerçitadas manos, y en la cautela del pie? (Palencia, 1996: 179).

Obsérvese cómo se vincula ejercicio y saber; se trata, por tanto, de una defensa de la necesidad del conocimiento práctico de la guerra. Alfonso de Palencia insiste en esta idea también en la guerra marítima ${ }^{11}$ e incluso la propia obediencia también admite la necesidad de ejercicio, recordando los ejemplos de la antigüedad clásica ${ }^{12}$. En esos años, la doctrina militar de Vegecio, que insistía en esos aspectos, era bien conocida (Martín Romero, 2015b: 96-99). El propio Mexía acude a Vegecio como autoridad en la cuestión que se edita aquí. Asimismo, Rodrigo Sánchez de Arévalo, en su Vergel de los príncipes defiende las excelencias del ejercicio de las armas (recordemos, de los caballeros, esto es, los nobles). Es más, Arévalo expresa ideas parecidas a las que encontramos en la cuestión de Mexía, pues defiende que el ejercicio bélico aumenta la fortaleza, esto es, el valor:

Asimismo, deste noble exercicio procede la esmerada fortaleza e esfuerço de coraçón, por la que los ínclitos reys e príncipes e los nobles varones osan acometer cosas terribles e peligrosas, quando e cómo conviene; ca por el uso e exercicio de las armas non solamente el cuerpo se abilita e rescibe mayores fuerças, mas aun el coraçón toma más osadía; de lo qual dice Tullio, que en los romanos la continua costunbre de pelear crio en ellos la gran audacia, por que cada uno con gran coraçón osó faser lo que havía bien provado (Arévalo, 1959: 319).

Arévalo continúa con más ejemplos de la antigüedad clásica que refuerzan su idea; cita a Suetonio, que afirmaba que la ausencia de práctica provocaba miedo, tesis que también se defiende en el texto del giennense:

E Svetonio, en el libro de Los doze Cesares, dize que los non exercitados en armas, quando se veen en las batallas e terribles peligros conviene que fagan una de tres cosas agenas de virtud: conviene a saber, o se espanten e mara-

\footnotetext{
11 "Enseñadas manos requieren, para qualquier cosa que se ha de fazer en el negoçio naval. Ninguna cosa del todo aprovecharán los mandamientos del Orden, sin prolongada exerçitación. Et los muy fuertes guerreros, quanto quier sean mucho queridos del Orden, si muchas vezes no ovieren sobido en navío, no solamente no podrán lidiar, mas assí como muertos, estarán feamente tendidos por torpe escañil de los moços" (Palencia, 1996: 180).

12 “Assí mesmo favoresçen las escripturas de los autores al vieio Exerçiçio, que otro tiempo prolongadamente ovo morado çerca del mesmo Rómulo y de los príncipes romanos; y afirman que la república romana aquistó tanto poderío por virtud del dicho Exerçiçio; y dizen aver sido esta no pequeña causa para que el pueblo romano sometiesse a las otras gentes que le sobrepuiavan en muchedumbre, riquezas e muchos dotes de la fortuna y del cuerpo" (Palencia, 1996: 182).
} 
villen por la gran novedad, o teman por falta de esperiencia, o fuya por mengua de coraçón, viendo peligros non acostunbrados (Arévalo, 1959: 319).

La conclusión de Arévalo en este punto coincide plenamente con la que defiende Mexía: "Pero los exercitados en armas non se maravillan de lo que muchas vezes han visto, nin temen de lo que han provado, nin fuyen del peligro que otras vezes han sufrido" (Arévalo, 1959: 319). Arévalo habla de las excelencias de diversos ejercicios que ha de practicar el príncipe, entre los cuales el primero, por ser considerado el más glorioso, es el militar. Por tanto, se habla de las ventajas del ejercicio bélico para el gobernante. Por su parte, el objetivo de Mexía no es otro que defender que quien ha pasado por los peligros de la guerra demostrará mayor fortaleza que quien aún no lo ha hecho.

Pero, ¿por qué Mexía defendía la segunda opinión? No podía ser de otra manera, si quería ser coherente con sus ideas expuestas en el Nobiliario vero. En este tratado defendía un concepto de nobleza apoyado en la sangre, que hoy día podríamos considerar racial, pero en el que se requería un proceso de depuración por medio del tipo de vida puramente aristocrático, proceso que implicaba, según el giennense, una mejora en cada generación, de forma que solo a partir de la cuarta se conseguían esos objetivos (Martín Romero, 2015a). Ese tipo de vida propio de la nobleza implicaba varios frentes, entre ellos una mejor alimentación, una educación más elevada y una vida orientada al ejercicio de la virtud. En este sentido, se trata de un proceso encaminado a la consecución de la perfección - que, en potencia se encuentra en la sangre- mediante la práctica continuada, la experiencia. Para defender su punto de vista recurre a todo un sistema de pruebas, argumentos y auctoritates. Entre las pruebas se encuentra la comparación y, en este sentido, resulta iluminador el momento en que recuerda la alquimia: de igual manera que para conseguir aguardiente el líquido ha de ser destilado en numerosas ocasiones, así se ha de pasar por diversas generaciones (al menos cuatro) para alcanzar que el linaje originado por un recién ennoblecido (que pasaría de plebeyo a hidalgo) pueda ser considerado noble (Nobiliario vero, libro II, cap. X). Posteriormente, en el capítulo XXVII vuelve a utilizar otra comparación de la "alquimia", en este caso, el agua de mercurio:

si así como el agua del mercurio es la quinta sustançia escondida, la cual por la suma bondad ayudante es traída a acto por magisterio, etc., la cual agua una vez purificada es linpia y, segunda vez, es más linpia y, terçera vez, más linpia, fasta en la cuarta vegada retificada no es dicha salvo agua, e, después de la cuarta vegada, es dicha mercurio o argén bivo, pues bien así a las dichas condiçiones fasta la cuarta generaçión ninguno puede ser dicho fijodalgo, etc. (Nobiliario vero, libro II, cap. XXVIII) ${ }^{13}$.

${ }^{13}$ Sigo mi propia edición con los mismos criterios de presentación gráfica que para la cuestión de Mexía que aquí edito. 
Ese proceso de depuración en cada generación se apoya, a su vez, en la adquisición de buenas costumbres (cada vez mejores y más asimiladas) y una mejor alimentación ${ }^{14}$. Pero es importante señalar la importancia que concede a esas "buenas costumbres", que pueden ser heredadas ("quien era virtuoso y fidalgo, las virtudes y buenas costunbres çierto es que sienpre le perteneçerán por vía hereditaria", Nobiliario vero, libro II, cap. 3); no olvidemos que dichas "buenas costumbres" implican el conocimiento y el ejercicio continuado de las virtudes, esto es, su práctica. Por tanto, si nobleza y caballería están vinculadas, el ejercicio (la práctica) de las virtudes militares será un requisito imprescindible para la nobleza. Es más, se requiere no solo el ejercicio de la propia vida, sino también las de los antecesores: se será tanto más noble cuantos más ancestros hayan seguido este tipo de vida:

Así después, toda criatura fue criada para nobleza, pues aquel que comiença a ser virtuoso $<\mathrm{s}>$ o a usar de buenas costumbres comiença a desear la dicha nobleza e lança fojas, las cuales son las buenas costunbres, [de las cuales costunbres] y apetito proçeden las flores, que son los nietos, y, de las flores, proçedió o proçede el fruto, el cual está en el fin al cual la planta se crio, y el tal fruto son los visnietos, los cuales ya están en el fin de la nobleza (Nobiliario vero, libro II, introducción para venir a tratar açerca de çiertos puntos).

De esa manera, linaje y práctica de las buenas costumbres van de la mano, en tanto que se pueden heredar. De ahí que Mexía rechace que el militar que aún no ha conocido la guerra sea mejor que el experimentado. Aceptarlo implicaría que el conocimiento y el uso -el tiempo o "antigüedad" necesarios para ello - supondrían una corrupción, una degradación del caballero, de manera que el recién armado caballero (esto es, el recién ennoblecido) sería mejor que el que lo es desde antiguo, porque no habría dado tiempo a que se produjera ese proceso de corrupción. Esto daría la razón a Sassoferrato (que defendía que el nuevo noble lo es más que sus sucesores) idea que Mexía rechazaba virulentamente porque destruía su sistema de pensamiento sustentado en la primacía de los linajes nobles y, entre ellos, de los más antiguos. Por tanto, ha de defender la necesidad de la práctica y del tiempo en el uso de las armas como formas de aumentar el valor y, por tanto, de mejorar. Rechazar esta idea sería tanto como admitir que un recién ennoblecido es superior a un miembro de un antiguo linaje quien — en la mentalidad de este autor — ha sido educado para ese tipo de

\footnotetext{
14 "como el que desçendido de alto y claro y antiguo linaje sea nudrido y criado por el contrario y en otra ordenada o reglada observançia açerca de moderada abstinençia o tenplança, asimismo de delicados, sotiles y dirigibles manjares, trae natural y aun hereditariamente más sotiles humores, lo cual es causa de asotalizar el ingenio, a elevar el entendimiento y a purificar y a generar más linpia y más pura sangre" (Nobiliario vero, libro II, cap. 29).
} 
vida y, además, ha heredado las virtudes de sus antepasados (quienes inicialmente ya habían demostrado pertenecer a una clase superior). Para Mexía habían de sucederse varias generaciones antes de que un miembro de esa familia pudiera denominarse noble porque consideraba necesario ese proceso de depuración que implicaba varias vidas. Por tanto, resultaba imprescindible que cada una de estas biografías estuviera orientada a la consecución de la perfección mediante la experiencia, el hábito y el uso.

Por otra parte, como se ha indicado, este autor parece referirse siempre a aquellos peligros procedentes del ejercicio bélico. En este sentido hay que recordar que para Mexía el origen de la nobleza era la caballería, entendida como el grupo social dedicado a la guerra (Martín Romero, 2015a). La necesidad de coraje en el guerrero determina la importancia de esta cuestión, si el hábito o la experiencia limitara el valor en el combatiente, este sería tanto mejor cuanto menos hubiera experimentado la guerra; esto destruiría el sistema de valores propuesto por Mexía. Si, por el contrario, el ejercicio bélico aumenta el coraje del guerrero, cuanto más haya conocido en primera persona la guerra, tanto más valeroso se mostrará y, por tanto, mejor caballero (esto es, noble) será. Mexía en esta cuestión no está hablando de otra cosa que no sea el estatus nobiliario, porque para él está íntimamente unido a la caballería; de ahí que la valentía del caballero determine su grado de nobleza. Si el tiempo, el uso y la experiencia aumentan dicha valentía, su nobleza también se ve incrementada.

Frente a quienes defendían la postura de Bartolo de Sassoferrato, Mexía defendía un concepto de nobleza de linaje, de sangre, que mejoraba con el paso de las generaciones. En este sentido parece seguir las opiniones de Sánchez de Arévalo, quien sostenía que existía un proceso de mejora de la clase guerrera por medio del ejercicio de las formas de vida aristocrática y bélica (Martín Romero, 2015a). Aunque Mexía defendía esta idea, partía, no obstante, de una tesis previa que lo diferenciaba de Arévalo. Para Mexía existía una distinción inicial, pues solo los mejores podían pertenecer a la clase militar. Para ello, recogió en su obra la conocida anécdota alfonsí de selección de guerreros, en la que todos los intentos fallaron hasta que se dio con la elección, no de los más sangrientos o más dados a trabajos viles, sino de aquellos que demostraban unas virtudes intachables, como el valor o la vergüenza, que les impedía huir ante los peligros. Esa clase — prácticamente un linaje aparte, esto es, una raza distinta - se vio mejorada por el paso del tiempo por medio de esas formas de vida típicas de la clase nobiliaria, educación, alimentación, ejercicio y alejamiento de oficios viles; todo lo cual determinaba la ventaja que los nobles demostraban frente a quienes no lo eran. En este sentido, junto a esa consideración racial de la nobleza, que determinó, según este autor, su elección inicial, aparece ese proceso de mejora por medio del comportamiento (y otros factores) propios de la vida aristocrática. 
Por todo ello, la tesis que defendía en esta cuestión resulta coherente con las ideas expuestas en el resto de su obra, pues se apoya en la necesidad de un proceso de depuración por medio de la práctica, del conocimiento y del ejercicio de la virtud, todo lo cual requiere algo que para Mexía es fundamental: el tiempo. A mayor tiempo de ejercicio y, por tanto, de conocimiento, mejor será el guerrero, más valiente y más versado. Esta idea no es inocente, en realidad está defendiendo que, si el guerrero es tanto mejor cuanto más se haya dedicado a la guerra, el noble (vinculado con el caballero o guerrero) será tanto mejor, es decir, tanto más noble, cuanto más haya practicado la nobleza (esto es, la caballería). Ese tiempo es, además, el requerido por medio del paso de generaciones para llegar a ser considerado verdaderamente noble; se trata de defender la primacía de los miembros de los linajes más nobles (identificados con los más antiguos) frente a los recién ennoblecidos. En definitiva, en esta cuestión Mexía no quiso dejar pasar la oportunidad de defender la necesidad de tiempo y experiencia en el caballero, porque de esa manera apuntalaba su pensamiento que brillantemente había expuesto en su Nobiliaro vero.

\section{CRITERIOS DE EDICIÓN}

Ofrezco la edición crítica de esta Cuistión de Fernán Mexía. Para ello he tomado como texto base el manuscrito BUS 2414 conservado en la Biblioteca Universitaria de Salamanca (la Cuistión ocupa sus fols. $175^{\mathrm{v}}-184^{\mathrm{v}}$ ), que he cotejado con el ms. BUS 2428 (fols. $167^{\mathrm{v}}-176^{\mathrm{r}}$ ), de la misma biblioteca. Posiblemente este segundo testimonio - al que llamo S2 en el aparato- no es sino una copia del anterior (Heusch, 2009); no obstante, en el aparato crítico ofrezco todas las variantes en los planos léxico y sintáctico. Para la presentación gráfica he seguido el texto base de acuerdo con las siguientes normas:

Transcribo $v / j$ cuando representan el valor consonántico $\mathrm{y} u / i$ cuando se trata del valor vocálico. Mantengo el reparto de las grafías $v / b$ tal como aparece en el impreso, así como los de $s / s s, c / c, c / z$ y $x / j$; transcribo $j / g$ ante $e, i$ tal como aparece en el texto. Transcribo como $q u$ - el grupo $c h$ - cuando representa el fonema oclusivo velar sordo. Por su parte, transcribo la $q u$ - con valor /qw/ como $\mathrm{cu}^{-}$, y la $y$ como $i$ con valor vocálico, semivocálico o semiconsonántico (salvo en los casos en los que actualmente se utiliza: $f u y \rightarrow f u i)$. Conservo el uso de $m / n$ antes de $b / p$ tal como aparece en el texto. No mantengo aquellas consonantes dobles que considero que no responden a una distinción fonológica. En cuanto a los nombres y referencias, edito los que aparecen en el texto base, aun en casos en los que quizá se haya producido un error de transmisión. Así, edito "Mesafo" (como padre de Camila, en lugar de la versión correcta, "Methapo", al no poder determinar si se trata de la lectura del autor o de un error de copia posterior. 
Transcribo el signo tironiano como $y$, pues es la forma más frecuente en el texto base. Resuelvo las abreviaturas sin ninguna indicación. Sigo las normas actuales para la unión y separación de palabras (aunque se marca mediante un apostrofo los casos de fusión por fonética sintáctica), para el uso de mayúsculas y minúsculas, y para el empleo de tildes (lo que me permite ofrecer mi opinión sobre la acentuación de cada palabra). Utilizo la tilde diacrítica para distinguir á (verbo) de $a$ (preposición). Las adiciones se marcan entre corchetes: [ ]. Por su parte, las supresiones se indican entre paréntesis angulares: \langle\rangle . Con el fin de ofrecer de forma transparente mi visión de la sintaxis del texto, he seguido las normas actuales de puntuación. Cuando las correcciones se corresponden con la lectura del otro testimonio, se indica en el aparato crítico. Se señala en tipo volado redondo la foliación del ms. 2414, mientras que la del ms. 2428 aparece en tipo volado cursivo.

175v Sobre la cuistión de yusso escripto, Fernán Mexía de Jaén limita y asigna ${ }^{15}$ las presentes rasones, la setençia y determinaçión de la cual remite y refiere y enderesça $a^{16}$ muy magnífico y ínclito señor, el señor don Álvaro de Mendoça, conde de Castro, señor de las villas de Gormás y Astudillo.

Acontesçe a las cossas muy graves y muy pesadas que, como son caídas de alto, non se pueden tener fasta que fallan lugar firme y costante do estar; pues, ¿cuál cossa más grave y pessada que la çiençia y saber, cuyas cuistiones son caídas de lo alto, que es la sabiduría? Pues las materias científicas y sotiles por su gravedad y pessadumbre commo viene cayendo non an ${ }^{17}$ lugar de reposso $y^{18}$ folgança $\mathrm{o}^{19}$ non fallan mensión en otro lugar salvo en ostales o cassas $^{20}$ de los varones sabios o prudentes, cuyos apossentamientos son propios logares de la dicha sabiesa, commo ospedaje quieto y perdurable de las materias ${ }^{21}$ de la sabiduría de que fablamos.

Pues que la pressente cuistión caída de lo alto de sabiduría es descendida ${ }^{22}$ buscando aquel logar ${ }^{23}$ sufiçiente donde puede yaser $\mathrm{o}^{24}$ repossar commo en propio estamiento suyo, el cual logar assás dificultosso $\mathrm{de}^{25}$ fallar es descendido y venido fasta la <heregia $>$ [egregia] merçed vuestra, y, entrada en vuestra ${ }^{26}$ possada, y, de vuestra cassa, al aposentamiento de la grant suficençia magnífica de vuestro ${ }^{27}$ sotil y

\footnotetext{
15 ASIGNA] S2: asigura

16 AL] S2: omitido

17 an] $S 2$ : ay

18 \&] S2: omitido

19 o] $S 2$ : e

20 cassas] $S 2$ : cosas

21 materias] $S 2$ : mas terias

22 desçendida] $S 2$ : desconcedida

23 logar] S2: lograr

24 o] $S 2: \mathrm{y}$

25 de] $S 2:$ de de

${ }^{26}$ en vuestra] $S 2$ : omitido

27 de vuestro] S2: y verdadero
} 
levadísimo entendimiento, considerando ${ }^{176 \mathrm{r}}$ que para su quietud y folgança eran nesçessarias dos cossas, cuyos efectos juntamente tarde se fallan, las cuales son çiençia o saber - a que llamamos teórica - y espirençia de los actos - lo cual nombramos plática - y, commo estas dos cossas de quien rasonamos - espeçialmente açerca de la disçiplina militar - relusan ${ }^{168 r}$ y resplandescan en vuestra merçed más ${ }^{28}$ que en ninguno de los otros grandes - fablando con reverençia de sus dignidades y merescimientos, lo cual non es $\mathrm{mi}^{29}$ voluntad $\mathrm{de}^{30}<$ preuidicar $>$ [prejudicar], mas acerca de los vuestros desir verdat-, demanda el absoluçión de aquestas dos opiniones de la subescripta cuistión, cuya determinaçión pertenesçe a vuestra magnifiçençia llena de prudençia y de espirençia, la cual non es menos que çiençia; por que humillmente los defensores de <armas> [amas] partes suplican a vuestra merced quiera determinar y absolver la dicha cuistión, en la cual a cada una parte yo he limitado y asignado rasones las más sufiçientes que yo he sentido, por rasón de las cuales vuestra merced avrá $\operatorname{logar}^{31}$ de setençiar en la potestad de tam penetrante y discreto ${ }^{32}$ saber tan maduro y tan delgado.

La cuistión es la siguiente: si aquel el cual nunca ovo sentido nin passado algunt trabajo y peligro temerá el peligro $<\mathrm{s}>\mathrm{y}$ trabajos tanto commo aquel que muchas veses sostovo $^{33}$, sintió y passó por muchos peligros y trabajos o si lo teme $<\&$ anos $>$ [menos] o los sofriráa ${ }^{34}$ mejor ${ }^{35}$ el que los sabe $y^{36}$ los sufrió. ${ }^{176 \mathrm{v}}$

Unos disen que aquel que non sabe de los peligros nin se vido en alguno que non $<$ que non $>^{37}$ lo temerá tanto commo aquel que los sabe y sintió y padesçió, eçetara. Los otros disen que aquel que sabe de muchos peligros, aquel los temerá menos.

Y porque las rasones de los unos y de los otros paresçe a cada parte sufiçientes, diremos aquí las unas y las otras, segunt la diversidad de las pressentes ${ }^{168 v}$ opiniones, commoquiera que yo confiesso sostener de la segunda y postrimera opinión, acostado a ella por rasón de la pura o mayor verdad, segunt que verdad es otrosí por el actoridad de los gloriossos testigos, la probaçión de los cuales, cuando ál sintiese, $<$ meptiría $>$ [mentiría] ${ }^{38}$ de mi propia actoridad, opinión o propósito.

Disen los primeros.

Cierto es que todo aquel que non sintió o non sabe de $<$ algut $>39$ [algunt] peligro non lo temerá; y para esto ay muchas rasones. La primera es que, bien así commo el dicho peligro de sí mismo es áspero y dificultosso de sostener $\mathrm{y}^{40}$ sofrir, aquel paresçe que non lo temerá antes que lo non sienta o conosca, porque el amar o aborresçer de las cosas non es salvo cuando son conoscidas. Pues, commo la dificultad y asperesa

\footnotetext{
28 más] $S 2:$ mal

$\left.{ }^{29} \mathrm{mi}\right] \mathrm{S} 2: \mathrm{ni}$

30 de] S2: omitido

31 logar] $S 2$ : lograr

32 discreto] $S 2$ : districto

33 sostovo] $S 2$ : los tuvo

${ }^{34}$ sofrirá] $S 2$ : omitido

35 mejor] $S 2$ : meror

${ }^{36}$ sabe y] $S 2$ : saber

37 Enmiendo atendiendo a la lectura de $S 2$.

38 Enmiendo atendiendo a la lectura de $S 2$.

39 algut] $S 2$ : algún

40 y] $S 2:$ e
} 
del peligro non es conosçida, cuidando ${ }^{41}$ que en el dicho peligro ay gloria, acontesce los omes pelear o verse en cualque peligro — commo muchas veses veemos a los mançebos- y entonçes ámanlo; otrosí ${ }^{177 r}$ después que yasen o sostienen el peligro, commo an sentido su dificultad y duresa y commo dentro del dicho peligro está escondida la espantable muerte, entonçes témenlo y aborrésçenlo, porque conosçen los dapños, las feridas, los trabajos, las penas y la proxemidad de la muerte, el conosçimiento de lo cual cabssa aborresçimiento, otrosí el sentimiento o conosçimiento, temor o miedo, ca el miedo non es ál sinon una esperança de algunt mal en el tiempo por venir, por rasón qu'el temor es más çierto aquel ${ }^{42}$ que sabe de los dichos peligros, ca los teme antes que en ellos esté, commo açidente de aquello que verná o podrá aveniri ${ }^{43}$; que, cuando somos en los peligros o males, ya el tal non es temor, segunt el filóssofo, mas dolor ${ }^{169 r}$ y tristesa.

La segunda rasón alega assí disiendo: çierto es que toda criatura naturalmente sobre todas las cossas la que más indefensamente ama es la vida; pues es claro que, tanto cuanto más delectable y entrañablemente amemos la vida, tanto más temeremos y aborresçeremos aquello que de la vida nos puede sacar. Pues commo los peligros son aquellos los cuales nos quitan la vida que avemos y tenemos por cara por medio de la muerte - la cual dise el filossofo que es la postrimera cossa de las espantables-, la cual magnifiesta la evidente espirençia, ca por el bivir es en la vida pressente todo nuestro trabajo, toda nuestra diligençia y toda nuestra providençia y todas las otras consideraçiones temporales, con las cuales siempre entendemos por conservar nuestra vida y por ${ }^{177 v}$ arredrar y apartar de nós nuestra muerte. Por do se concluye que commo aque[1] el cual conosçe y sabe de los dichos peligros - los cuales nos çertefican de la muerte y nos amenasan con destruimiento o desfasimiento de la vida tan amada-, qu'el tal más temerá el espramento de la batalla o la prueva de los peligros y aquel el cual ha en inorançia el exerçiçio bélico o de batalla o los dichos peligros menos los temerá.

La terçera rasón siguiendo disen: otrosít ${ }^{44}$ es manifiesto que la cossa más amable y más deseable después de la vida es la salud; esto declara toda la condiçión humana desde los omes raçionales fasta las animalías, commo paresçe notoriamente, ca en sus enfermedades cada una segunt su calidad o espeçie luego adquiere aquello que le puede aprovechar açerca de su calidad; y tanto más nós, las criaturas de rasón, por la superioridat que açerca d'ellas tenemos, ca por la salud tenemos diligençia en buscar físsicos o remedios mediçinales; y non ${ }^{45}$ tan solamente buscallos, mas suplicallos, rogallos $\mathrm{y}^{46}<$ saliriallos $>$ [saludallos]; assimismo, respectando ${ }^{169 v}$ el benefiçio de la salud, fuimos los lugares infiçionados, los úmidos ${ }^{47}$, los dolientes, y con grant diligençia buscamos los lugares sanos, amigables y conformes a nuestras complissiones y calidades; buscamos que sean iuales, moderados y atemperados açerca de la grandesa del frío ${ }^{48}$;

\footnotetext{
41 cuidando] $S 2$ : cuidado

42 aquel] $S 2$ : en aquel

43 avenir] $S 2$ : venir

44 otrosí] S2: omitido

45 non] $S 2$ : voz

46 y] $S 2: 0$

47 úmidos] $S 2$ : unidos

48 frío] $S 2$ : rio
} 
otrosí açerca del exçesso del calor buscamos que sean de aires muy sotiles y saludables; y buscamos commo podamos ${ }^{178 r}$ bevir en cassas sanas, alegres y plasibles, por la consolaçión y recreaçión de nuestros spíritus y folgança del coraçón; y assí de las otras cossas. Pues esto todo ${ }^{49}$, ¿a qué fin ${ }^{50}$ ? $\mathrm{El} \mathrm{fin}{ }^{51}$ es rasón de adquirir e conservar salud. Pues commo los peligros son aquellos los cuales terresçen y destruyen nuestra salud, síguesse que conosçiendo y sabiendo cuál es el peligro el cual es cabsa de feridas, de golpes, de trabajos, de penas, de dolençias y de muerte y de otros inconvinientes, si se pueden desir, los cuales paresçe y quitan de salud, síguesse que nos pornán en mayor miedo, commo aquellos que sabemos y entendemos que nos roban y arrebatan el bien de la salud. Luego de nesçessidad se concluye que aquel que sabe el spirmento de los peligros, trabajos y batallas más temerá $<\mathrm{n}>0$ mayor miedo avrá antes d'estar en el dicho peligro que aquel el cual non sabe ni sopo de los dichos peligros nin se falló en ellos.

Los segundos disen que, non obstantes las dichas rasones, que menos temor o miedo avrán aquellos los cuales más peligros avrán sentido, visto o provado. Y pruévanlo por las siguientes rasones, allegando dichos de grandes sabios y esçelentes varones, otrosí por enxemplos.

Açerca d'esta primera rasón disen: nuestra conpusiçión humana ovo desd'el prinçipio del primero padre después que pecó una natural flaquesa por medio de la cual todas las ${ }^{170 r}$ cossas a nós non conosçidas oviessen de nos espantar y atemorar, en espeçial cuando non pensadamente aquellas ${ }^{178 v}$ sobreviniesen. Pues, como así los más de los peligros vienen por otra vía de commo son considerados, es nesçessario que nos espanten; y tanto más cuanto menos de aquellas ayamos sentido, provado y visto; la rasón es porque no sabemos a qué verná el dicho peligro. Pues çierto es que aquel $a^{52}$ cual de súbito vino el peligro o que del peligro non sabe cuando çerca d'él estoviere más lo temerá, ca el tal, puesto que non sabe del peligro de la batalla, commo non lo ha visto, sentido nin provado, pero sabe que mataron a Magón y Asdrúbal, y que fueron y vençieron a Hanón; y, commo non sabe nin á el sentimiento o sperimento de los avenimientos de las batallas, siempre sospecha $<\mathrm{n}>{ }^{53} \mathrm{o}^{54}$ piensa lo peor, ca non considera que lo ferirán o $10^{55}$ retraerán, mas que lo matarán o del todo lo vençerán; y d'esta cabssa ${ }^{56}$ teme y recélasse más y conçibe gran miedo; y el otro que muchas vegadas peleó, vido y provó romper diversas batallas sabe por la ispirençia gra[n]de de las batallas que fue ferido y, ferido, que vençió; otrosí que fue llagado e que ${ }^{57}$ las grandes llagas sanó y que las cossas arduas y diversas que açerca de las batallas acontesçen, que muchas veses las sufrió; y non solamente por la grande ispirençia y prueva ya non las teme mucho, mas antes las menospresçia. Esto afirma el Vegeçio, Re militari, en el libro terçero, disiendo: "aquellas cossas que son muy ussadas y son menos temidas"; en el capítulo treinta VI y final, de las reglas generales, dise: "las

\footnotetext{
49 todo] S2: omitido

50 fin] $S 2$ : fui

51 fin] $S 2$ : fui

52 a] $S 2$ : al

53 Enmiendo atendiendo a la lectura de $S 2$

54 o] $S 2$ : et

55 lo] S2: omitido

56 d'esta cabssa] $S 2$ : d'este modo

${ }^{57}$ que] $S 2:$ de
} 
cossas sobtossas e pocas vegadas venidas o vistas espantan y las usadas se envilesçen y despresçian"; en el libro primero ${ }^{179 r}$ dise: "no es cossa ninguna por difíçil que sea que el usso o continuaçión non la faga o torne digera"; pues çierto es que naturalmente somos medrossos, salvo que la virtud nos induse a fortalesa, ${ }^{170 v}$ pues, ¿cómmo seremos fechos esforçados? Serlo emos exerçiendo y abituándonos mucho açerca del sostener, ussar y provar los peligros, y non solamente un peligro, mas muchos, ca un acto non cabssa perfectión de virtud, así lo dise el filossofo en el primero de su Ética. Açerca de lo cual tenemos infinitos enxemplos, ca sabemos cómmo Nuestra Señora se espantó en el prinçipio de la salutaçión commo el santo ángel le aparesçió, pero después non ovo el dicho temor nin alteraçión en las otras vegadas muchas ${ }^{58}$ que le aparesçió este casso, el usso y continuaçión de ver ángeles después de aquella; esto mismo acaesçió a muchos santos profectas, assí commo a Issaías, a Sacarías y a Daniel y a otros que se dexa por la brevedad.

La segunda rasón: sabemos que toda nuestra vida humana es esforçada y acreçentada açerca de todos los actos por una costumbre la cual nos enderesça y allega a perfiçión; y es así, como de suso es dicho, naturalmente somos temerosos; pero pongamos $\operatorname{cossa}^{59}$ que podemos ser esforçados y fuertes, esto es a natura, lo cual es negado sin dubda, por alguna cabtela de la militar disçiplina y enseñança podemos venir a posseer virtud de fortalesa, como manifiestamente avemos visto en muchos, ca sabemos que Martín ${ }^{60}$ Gomes, un cavallero del Çid antes que ${ }^{179 v}$ supiesse los peligros, trabajos y advenimientos de las batallas fue muy covarde y temerosso, pero, después que supo, provó y acostumbró y ussó los peligros de las batallas y los continuó y provó, fue uno de los buenos cavalleros del mun[do] ${ }^{61}$.

$\mathrm{Y}$, por tanto dise bien el filóssofo en el libro mençionado: "non es pequeña difirençia la bondad y virtud estar en potençia o en acto, y en operaçión ${ }^{171 r}$ y uso"; dise en el segundo libro: "las virtudes proçediendo o progistiendo en nós avemos el acto y perfiçión", esto es por un exerçiçio $0^{62}$ continuaçión; y así somos fechos virtuosos, que se entiende esforçados o fuertes, do se sigue el propósito el cual es que nuestra natural flaquesa traemos a virtud de fortalesa mediante la costumbre y usso, ca dise el dicho filóssofo: "según las cossas que ussamos [y] acostumbramos faser, tales actos son en nós engendrados"; dise más, en el capítulo, libro resçitado, en tres maneras se fasen los omes fuertes $0^{63}$ virtuossos o buenos, dise que unos por natura, otros por luenga costumbre o uso, otros por luenga costumbre [y] doctrina. Dise: "lumbre de provechosa vida, tal será nuestra vida cuales serán nuestras obras", ca non se puede negar que las cossas muchas veses fechas o mandadas faser non se muevan y que los enseñamientos de los sabios y provados non aprovechen, lo cual es nesçessario, ca la luenga costunbre de las cossas nos fase muy ábiles, dispuesto[s] y libres para las fasser e nos trueca y cambia nuestra naturalesa, ca toda perfiçión se alcança con trabajo, con exerçiçio, con uso y continuaçión; así lo afirma don Enrique en una glossa sobre el libro terçero de la ${ }^{180 \mathrm{r}}$ Eneida; lo cual testiguan muchos ensemplos, segunt paresçe en

\footnotetext{
58 vegadas muchas] $S 2$ : muchas vegadas

59 cossa] $S 2$ : caso

60 Martín] S2: Ruy

61 Enmiendo atendiendo a la lectura de $S 2$.

62 o] $S 2$ : et

${ }^{63}$ o] $S 2$ : et
} 
los judíos, ca por la grant costumbre de ser siervos, cabtivos y medrossos son fechos naturalmente medrosos y covardes; ca çierto es que, en tanto que Muissén, Jossué, Jedeón, Saúl y David fueron entre ellos, otrosí el pueblo ${ }^{64}$ de Israel fue libre y en él ovo omes cavallerosos y batalladores, fueron fuertes y muy esforçados mucho en el dicho pueblo, commo paresçe en el proçesso de los dichos prínçipes, en el cual son vistos y fallados varones muy virtuossos y fuertes, segunt que fueron los macabeos y otros muchos, así como Matatías, Judas, Eleasar, Simeón, Jonatás e Johanua, assimismo como se lee de Joab ${ }^{65}$, de Calef, de ${ }^{171 v}$ Jonatán y otros, los cuales fueron de los esforçados omes del mundo, cuya virtud en el dicho pueblo por el desfallesçimiento del usso, de la $^{66}$ costumbre, del espíritu de la graçia y batallas $<$ soy $>$ [son] oy los del dicho linaje muy covardes y tristes.

Otrosí dentro de la flaquesa nuestra es mesclada otra mayor flaquesa y es aquella la cual es fallada y vista en la generaçión de mugeres, commo es çierto que aver en ellas fortalesa según natura por parte de su friesa ${ }^{67}$ es casi contradesir o repunar natura, pero sabemos de $<$ muchos $>$ [muchas] y casi $<$ infinitos $>$ [infinitas] que fueron $<$ esforçados $>$ [esforçadas] y fuertes, tanto que a muchos prínçipes vençieron y a otros avergonçaron; lo cual segunt verdad fiso el usso y costumbre de los peligros; lo cual pareçe en Semíramis, reina de Babilonia, la cual seyendo flaca y temerosa muger, segunt natura, el usso y costumbre de las batallas la fisieron ossada, atrevida, ${ }^{180 v}$ y muy esforçada, tanto que segunt el Justino y otros estoriadores sobrevençió y mató al rey Çiro. Asimismo paresçe en las amasonas, segunt que se lee en las estorias del Trogo Pompeo, de Claudio y de otros muchos, los cuales disen que, después de la muerte del rey Canaso, las dichas mugeres quedaron flacas y temerosas en sus tierras $\mathrm{y}$, commo fueron cometidas, metiéndose a defensión començaron a cobrar ossadía, ca por la nesçessidad tomaron armas para se defender; e después, otra vegada cometidas por sus vesinos ásperamente para las llevar robadas, las cuales ya avissadas, ussadas y acostumbradas en algunos peligros y en armas arredráronlos de sí, con gran vergüença d'ellos, $10^{68}$ cual costumbre y usso las fiso fuertes y esforçadas; según se lee de Marpetia, de Marpessia, de Sinope, de Edripa ${ }^{69}$, de Ipólita, la cual casi vençido y desbaratado $^{70}$ tovo al fuerte Tesseo ${ }^{71}$, otrosí de Pantasilea, la cual fiso muchas vergüenças ${ }^{172 r}$ a muchos prínçipes griegos, de Tamaris, a quien la costumbre y usso de los dichos peligros fisieron así menospreçiadoras de los avenimientos y de los trabajos de las batallas que los non tenían; otrosí se lee de Camila virgen ${ }^{72}$, a $<a>$ la cual el grant usso y costumbre y la criança entre las animalías fieras fasíale non $\operatorname{temer}^{73}$ los tigres nin los otros animales crueles, ca es de saber, segúnt el Virgilio, en el libro XI, capítulo XIX de su Eneida, dise: "Mesafo, su padre, la crió en lugares ásperos y peligrosos,

\footnotetext{
${ }^{64}$ pueblo] S2: omitido

65 de Joab] $S 2$ : en Jacob

66 de la] $S 2$ : de la de la

67 friesa] $S 2$ : firesa

68 lo] $S 2$ : la

${ }^{69}$ Edripa] S2: Odripa

70 desbaratado] $S 2$ : desfaborezido

71 Tesseo] S2: omitido

72 virgen] $S 2$ : vergez.

73 temer] $S 2$ : tener
} 
cuyo reposso y estado eran en los escondimientos de $<$ las $>$ [los] espantables $<$ cárçeles $>^{74}$ [çarçales], la cual non temía la ${ }^{181 r}$ mortal bívora nin la cruel ${ }^{75}$ serpiente ni el bravo león ni la ligera tigre ni los inhumanos ${ }^{76}$ çiropes, antes traía la crinada piel de la tigre por guarniçión ${ }^{77}$ de su manto y con mano viril - dise el actor- rodeava el dardo y con la fonda derribava el bolante çisne".

Así que es de concluir y afirmar por los dichos exemplos los cuales declaran cómmo la costumbre, husso y exerçiçio de los peligros nos ${ }^{78}$ fasen o pueden faser menos temerossos; afírmalo el Vegeçio en el libro segundo, capítulo XXXVI, "Natura ${ }^{79}$ pocos varones ará ${ }^{80}$ fuertes, mas $^{81}$ la buena enseñança y uso a muchos fase ardides y fuertes".

La terçera rasón siguiendo, disen que los peligros ussados y provados son menos temidos. Muéstranlo ${ }^{82}$ dos cossas otras: la una, la prueva de muchos gloriosos varones; la otra, el enxemplo de muchas y diversas condiçiones de omes. La primera pruévasse

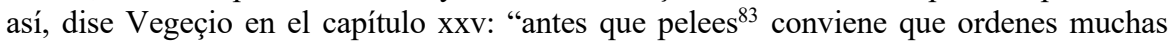
veses tu hueste ${ }^{84}$ en hases en lugares seguros, ca las cossas que mucho son ussadas non se temen tanto"; en el prólago del segundo libro De re militari dise: "el cabdillo deve ser escogido el cual sea prínçipe ardid $^{85}$, esforçado, sofrido ${ }^{86}$, sabidor, acuçiosso y artero en pelear y tal que sepa y pueda enseñar el arte y usso de las armas y de la pelea, lo cual fasen a los ${ }^{172 v}$ que lo saben ser ossados y sin temor y de grant coraçón, que no es ninguno que tema faser lo que bien sabe, ca lo fase sin miedo"; en el prinçipio del prólago dise: "todas las cossas por usso y por costumbre se acresçientan y conservan, así pequeñas como grandes"; pues asír es que todas las cosas acreçientan el usso, abituaçión y costumbre, luego síguesse qu'el usso de los peligros de los trabajos y de las batallas acreçentará esfuerço y multiplicarse á la virtud de la fortalesa y amenguarse á el defecto de la covardía y miedo, ca aún esto quiere desir Séneca allí donde dise que la mucha converssaçión cabsa menospresçio; pues ${ }^{181 v}$ luego la grant continuidat, costumbre de sofrir y sostener peligros y trabajos y advenimientos diversos de batallas, cabsa será singular de menospreçiarlos y no temerlos.

La segunda por donde se prueva, la cual es los enxemplos de diversas condiçiones de omes, es assí: claro es que la dicha ${ }^{88}$ conclusión es contradicha commo vemos açerca de los peligros de la mar, ca los marineros porque son ussados y acostumbrados

\footnotetext{
${ }^{74}$ carçeles] $S 2$ : celes

75 cruel] $S 2$ : çivil

76 inhumanos] $S 2$ : humanos

${ }^{77}$ por guarniçión] $S 2$ : gravición

78 nos] $S 2$ : no

79 natura] $S 2$ : nata

${ }^{80}$ ará] $S 2$ : sera

${ }^{81}$ mas] $S 2$ : he mas

${ }^{82}$ Muéstranlo] $S 2$ : muestralo

${ }^{83}$ pelees] $S 2$ : Apeles

${ }^{84}$ tu hueste] $S 2$ : tubiste

85 ardid] $S 2$ : David

${ }^{86}$ sofrido] $S 2$ : lo fido

${ }^{87}$ así] $S 2:$ si así

${ }^{88}$ dicha] $S 2$ : dicha condición
} 
en los dichos peligros non los temen o témenlos poco; de manera que, si los que ${ }^{89}$ los tales peligros no han ussado se veen en ellos, el miedo es tan comportable que non se puede imaginar, segunt que sabemos por familiar ispirençia, ca los tales en tales puntos de solo miedo casi resciben muerte; y de los ussados y acostumbrados de las tormentas y fortunas de la mar muchas y infinitas veses sabemos ser acaesçidos los peligros de la mar mesma ser ${ }^{90}$ de tan grant fortuna y de tan gra[n]de ${ }^{91}$ réfagas $^{92}$ de vientos, do es menester grant fortalesa, agora para el governar, agora para pujar o calar las velas, agora para sobir a las gavias; los cuales peligros si non fuesen muchas veses ussados, imposible y dificultossa cosa sería sostenerlos.

Otrosí acaesçe ${ }^{173 r}$ sobrevenir batallas de otras armadas, a do es menester otros nuevos remedios, porque son nuevos peligros ${ }^{93}$ en los cuales los que non los han visto por la mayor parte se espantan, de manera que son ligados de gran turbaçión y desmayo; lo cual fase por lo contrario el que los ha ussado y acostumbrado.

Otrosí aquel ${ }^{94}$ que nunca ${ }^{95}$ vido el león ¡cuál es el miedo que altera el $^{96}$ inoçente coraçón suyo! Sin dubda paresçe que apenas ossa combatillo, mas aun dificultossamente miralla; pero vemos que un pequeño ombre por $10^{97}$ aver ussado acostumbrado no solo combatillo, mas acontesçe hussar casti[ga]llo con un palo y ençerrallo o desterrallo juntamente o faselle echar o levantar de consuno.

Asimismo sabemos que unos ombres de generaçión muy ${ }^{182 \mathrm{r}}$ pequeña, los cuales abitan çerca de la ribera del Nilo, que a las fieras y $<$ qudelissimas $>{ }^{98}$ [crudelissimas] cocatriçes dentro del agua profunda del Nilo las matan en unos cavallillos pequeños con un bastón y con grandes boses teniéndolas ${ }^{99}$ por las colas fasta que mueren. Por çierto non sería fortalesa de ningunt varón que assemejable peligro non oviesse provado qu'en penssar de lo acometer non oviesse gravíssimo miedo incomparable, del cual peligro son testigos en las glossas sobre la general del mundo el maestro Eusebio, Orosio, el Gerónimo.

Otrosí los ballesteros de monte o los monteros por aver hussado los peligros de los venados, ossos, puercos y otras animalías non los espantan, nin los tales cuales ${ }^{100}$ an grant miedo; y non solo non an miedo, mas muchas veses les acaesçe aver ${ }^{101}$ batalla con ellos, do los vençen, fieren y matan; nin vellos sobtossa nin arrebatadamente les pone miedo, lo cual espanta y altera a cualquiera - por fuerte varón que sea - si semejante d'él son vistos; ca es de saber que Pireteo, por no aver visto semejabel animal del Cançervero, se turbó y espantó, puesto qu'él fuesse ome esforçado, del cual espan-

\footnotetext{
${ }^{89}$ los que] S2: omitido

90 ser] $S 2$ : es

91 Enmiendo atendiendo a la lectura de $S 2$

92 réfagas] $S 2$ : refugas

93 nuevos peligros] $S 2$ : menos peligrosos

94 aquel] $S 2$ : el que

95 nunca] $S 2$ : non

96 el] $S 2:$ al

97 lo] $S 2$ : la

98 \&qidelissimas] $S 2$ : inquidelissimas

99 teniéndolas] $S 2$ : teniendo teniendolas

100 nin los tales cuales] $S 2$ : criales aran

101 aver] S2: avra
} 
to y temor turbado ovo lugar de lo tragar el dicho animal; otrosí Tesseo, inorante de tan ${ }^{173 v}$ esquiva visión como era la del dicho can, espantosse, de cuyo miedo y espanto fue desbaratado del espantable animal; pero commo el famosso Ércoles fuesse varón acostumbrado y ussado de tales peligros, commo d'él fue visto, non se espantó de la inorme figura y no espantado nin medrosso de los fieros ladridos vígoramente le combatió y vençió; del cual vençimiento se sigueron dos cossas: la una, que libró a Tesseo del dicho lugar; la otra, que ató con cadena de tres collares las tres gargantas del grant Cançervero esquivo y infernal.

Lo cual destruye la dicha primera opinión y afírmala y apruéva la segunda, la cual defendemos testigando muchos actores, espeçialmente Séneca en sus tragedias, don Enrique en sus Trabajos, Juan Bocaçio en sus Caídas, en el libro terçero, capítulo XLV, disiendo: "así commo al pastor paresçe el fuego más caliente que al ferrero, así el angostura es visto más dura al que nunca la vio nin la provó \&c."; a nuestra ${ }^{182 v}$ defensión ayuda o aparesçe ayudar el Dante en su Comedia, libro primero, capítulo primero, porque commo el dicho actor se fallasse en aquella vissión e lugar espantable en cuyo comienço ovo miedo terrible, pero, como fuessen hussando el dicho peligro y espanto, fuelo no tanto temiendo; y díselo por estas palabras: "commo fue junto al pie de un collado do se acabava el valle, de miedo me pungía el coraçón, empero caté en lo alto a las espaldas ya vestidas de los rayos de la planeta y entonçes ya fue un poco el temor haquedado".

La cuarta rasón es: dise el filossofo en el libro sesmo ${ }^{102}$ de sus Éticas: "çinco son los actos y ábitos intelletuales açerca de los cuales el ánima ${ }^{103}$ siempre entiende la verdad sin ser desçebida ${ }^{104}$ de la falsía, los cuales son arte, çiençia, prudençia, sabiesa y entendimiento". Pues como el arte sea un ábito tan prinçipal, según que dize el dicho filóssofo, y los ${ }^{174 r}$ advenimientos bélicos los cuales conduzen los peligros y los peligros al dicho miedo, el cual miedo por virtud del arte, de las espirençias, del usso, de la prueva y de la costumbre en el varón sabidor de la tal arte y disçiplina - digo militar o de batallas, do yasen los peligros - ya serán moderados y atemprados, el cual amoderamiento ni atempramiento no podrá aver aquel el cual inora la dicha arte y disciplina y sus pruevas y sus ispirençias, que son rasón o cabssa de amenguar o desfaser el mi[e]do.

Açerca de lo cual < dize> dise Visión Delectable en el capítulo De fortalesa: "los otros son fuertes por costumbres, ca aviendo seído en muchas batallas a los cuales ha ido bien, aquella confiança fázelos ossados"; esto $<$ s $>$ afirma el $<$ Fernando $>$ [filósofo] en el cuarto de su Ética \&c.

La quinta rassón es: en todas aquellas rasones en las cuales ay menos de conosçimiento, sabemos notoriamente aver mayor sospecha; pues luego síguese ${ }^{183 \mathrm{r}}$ que en aquel $\mathrm{do}<\mathrm{n}>$ no avría esperimento nin prueva nin usso nin costumbre de batallas nin de otros trabajos más sospechas avrá. Pues, si más o mayor cantidad de sospecha avrá, no es de dubdar que más y mayor miedo terná, ca de la grant sospecha nasçe el miedo commo de fuente radical y prinçipal do hase fundamiento y procreaçión; açerca de lo cual dise el filóssofo en el libro nombrado: "son dos ábitos açerca de los cuales muchas veses o las más el ánima es desçebida y estos son opinión y sospecha".

\footnotetext{
102 sesmo] $S 2: 10$

103 ánima] S2: omitido

104 desçebida] $S 2$ : conscevida
} 
Agora pues concluyendo digo que todo aquel el cual por espirençia y prueva á passado y visto muchos peligros temerá menos los peligros, los trabajos, los inconvinientes y daños de las batallas y de las otras cossas, como sufre mejor el labrador el rigor y fuerça de los rayos del sol en meitad del estío y los otros trabajos, otrosí ${ }^{174 v}$ los cavalleros o varones ussados o acostumbrados de traer o comportar el crudo arnés en las guerreras huestes, que non el fijo del mercader, ussado y acostumbrado estar $^{105}$ en la tienda emparamentada y toldada $<\mathrm{s}>106$ de ricas sedas y paños finos; otrosí acontesçe el <ascor $>^{107}$ [açor] o al falcón cuando son nuevos $<$ viejos $>$, los cuales inoran las prissiones, de su natura espantarse d'ellas, pero, después de ussadas y acostumbradas, non solo a sus raleas acontesçe acometer, mas al águila ossada y atrevidamente. A esto paresçe ayudar el Valerio y el Tulio y el Vegeçio, los cuales escujeron del grande estudio y de la gran cura que ovieron los laçedemones y grant uso y costumbre açerca de las batallas, de cuya disçiplina y costumbre disen resultar ser los más esforçados varones del mundo, otrosí los primeros inventores del arte y disçiplina de batallas; assimismo David, por la gran costumbre que ovo guardando el ganado de su padre y esse ${ }^{108}$ previno cometer a los osos y a los leones y matallos; esto quiso dezir ${ }^{183 v}$ él cuando Saúl le desía que era pequeño para lidiar con él filisteo, ca le dixo qu'él hera ussado, provado y acostumbrado de correr tras el osso, el cual afogava con sus manos. Otrosí segunt el Tito Libio, libro IX de su Segunda década, dize los numidianos los más d'ellos eran gente que nuevamente avían tomado armas y non avían uso nin costumbre d'ellas, non sufrieron a los romanos y fueron luego vençidos; el Dante en el libro primero de su Comedia, I capítulo, dise: "era el comienço de la mañana cuando se mueven las cosas bellas, do el esperar de la fiera de la fiel piel engañosa me era ocasión la ora, el tiempo, la dulçe estança, mas non así que miedo non me diesse"; da a entender el dicho actor que, puesto que la ora, el tiempo ${ }^{175 r}$ fuessen causa $^{109}$ de no tener ni aver miedo (por ser al alva), pero que, commo aquel animal de la piel engañosa vido, non pudo estar sin temor e miedo; esto era porque non avía usso ni costumbre de ver semejante animal, el cual estorvava su camino; en el segundo capítulo dize: "commo quien desquiere lo que quiere y del comienço se quita, así fise en la escura cuesta, <estg la que resta $>110$ [estragué la recuesta] en el comienço tanto duro", dise: "respondió aquella sombra: «ió, cuánto tu coraçón es lleno de vilesa y miedo o d'él111 ofendido!»"; el Tito Libio en la Segunda década pone que fablando Çipión con Quinto Fabio sobre la passada suya a África dixo las palabras siguientes: "Mayor corasçón y mayor esfuerço ha el que fase guerra a otro que non el que defiende su tierra por guerra; otrosí mayor miedo toma ome de las cossas que non sabe nin conosçe que de las cossas que conosçe y sabe"; y claro paresçe que más tememos y resçelamos o más miedo nos pone un enemigo nuevo y non conosçido que non aquel con quien ussamos y acostumbramos hazer o sostener guerra; porque los nuevos cassos o nuevas contigençias más arduos, más graves y más pungitivos açedentes nos cabssan $\mathrm{y}$ con mayor fuerça y alteraçión ${ }^{184 \mathrm{r}}$ inpugnan y tientan nuestra virtud.

\footnotetext{
105 estar] S2: husar et estar

106 Enmiendo atendiendo a la lectura de $S 2$.

107 ascor] S2: alcor

108 esse] él se

109 causa] S2: omitido

110 estg la que resta] $S 2$ : este la que resta

111 d'él] $S 2$ : de lo
} 
El Virgilio en el libro deseno de su Eneida, capítulo XV, dise que cuando Eneas y Palante, fijo de Emandro, rey de los latinos, llegando a la ribera donde avían de desenbarcar, cerca de aquella nueva çibdad o poblado estava o avía quedado Yulo Escanio $^{112}$, fijo del dicho Eneas, que fallaron a los rótulos con Turno, su rey, y como el dicho peligro fue súbito y nuevo, espantáronse y ovieron grande miedo porque en otro tal non se eran vistos; dise el dicho actor que visto por Turno el miedo de aquellos dixo contra los suyos: ${ }^{175 v}$ "entremos a los troyanos en el agua mientras están temerosos y salidos delesnan en las primeras pisadas".

$\mathrm{Y}$ non es de dubdar, ca çierto sabemos y vemos que un vaquerizo, por la grant avituaçión, uso y continuaçión que ha de ver tractar los fieros y bravos toros, non los teme, antes muchas veses acontesçe con su solo cayado allegar o arredrar de los lugares do está el sobervio y muy bravo toro y algunas vezes aver batalla con él sin otras armas, pues ¿quién puede creer que si el dicho peligro esquivo y áspero non fuese por él provado, ussado y acostumbrado non solamente non lo osaría cometer, mas por fuerte que fuesse fuiría del tan espantable animal? Açerca de lo cual dise: "Lumbre de la provechosa vida, la virtud non viene en coraçón que non es enseñado nin dotrinado y llevado a perfiçión por soberano exerçiçio".

El Vegeçio en el cuarto De cavallería dise: "cuando algunt temor es en la hueste, el sabio duque deve husar de la semejante astuçia: antes que se combata ordene a menudo su hueste en los más seguros lugares; y acostumbre y husse su gente a ver los enemigos y conosçerlos; y vean y conoscan sus costumbres de los adversarios y las armas y los cavalleros \&c."; do paresçe qu'el dicho actor el presente consejo da por singular remedio pero para partir la gente de miedo, la cual segunt el presente consejo por medio del husso y ${ }^{184 \mathrm{v}}$ costumbre del hordenarse la batalla; otrosí por la continuaçión de ver y conosçer los enemigos non eran o non son así temerossos nin los adversarios les paresçerían o paresçen tan espantables y fuertes.

Lo cual defasse y destruye la primera opinión y concluye el dicho propósito de la segunda, el cual es ${ }^{176 r}$ sostener que mayor miedo ha aquel el cual ${ }^{113}$ non tiene ispirençia nin usso nin costumbre ni prueva açerca de los peligros y trabajos que non aquel que es criado entr'ellos o á sostenido, exerçitado y provado munchos ${ }^{114}$.

\section{BIBLIOGRAFÍA}

Alvar, Carlos (2010): Traducciones y traductores. Materiales para una historia de la traducción en Castilla durante la Edad Media, Alcalá de Henares, Centro de Estudios Cervantinos.

Alvar, Carlos (2015): Presencias y ausencias del rey Arturo en España, Madrid, Sial Pigmalión.

Alvar, Carlos y José Manuel Lucía Megías (2009): Repertorio de traductores del siglo XV, Madrid, Ollero y Ramos.

Arévalo, Rodrigo de (1959): "Vergel de los príncipes", en Mario Penna, Prosistas castellanos del siglo XV, Madrid, Atlas, pp. 311-341.

Chas, Antonio (2000): Amor y corte, la materia sentimental en las cuestiones poéticas del siglo $X V$, Noia, Toxosoutos.

\footnotetext{
112 Estanio] S2: escarrio

113 es sostener (tachado)

114 S2: Finis coronat opus (add.)
} 
Gómez Moreno, Ángel (1985): "La Qüestión del Marqués de Santillana a don Alfonso de Cartagena”, El Crotalón, II, pp. 335-363.

Gómez Moreno, Ángel (1994): España y la Italia de los humanistas. Primeros ecos, Madrid, Gredos.

Gómez Redondo, Fernando (2007): Historia de la prosa medieval castellana IV. El reinado de Enrique IV: el final de la Edad Media. Conclusiones. Guía de lectura. Apéndice. Índices, Madrid, Cátedra.

Gómez Redondo, Fernando (2012): Historia de la prosa de los Reyes Católicos: el umbral del Renacimiento, 2 vols., Madrid, Cátedra.

Hamlin, Cinthia Maria (2013): "La traducción de la Divina Comedia de Villegas: problemas de datación y filiación de testimonios", Letras, 67-68, pp. 107-116.

Heusch, Carlos (2009): "Le Chevalier Ferrán Mexía et son Nobiliario vero (1492): de l'imaginaire chevaleresque à la logique de l'exclusion", Atalaya. Révue d'Études Médiévales Romanes, XI, <http://atalaya.revues.org/598>.

Huizinga, Johan (2005): El otoño de la Edad Media, versión española de José Gaos, Madrid, Alianza.

Lucena, Juan de (2004): De vita felici, Olga Perotti (ed.), Pavia, Ibis.

Martín Romero, José Julio (2012a): "Bartolo de Sassoferrato y Hernán Mexía: el Nobiliario Vero en su contexto histórico", en Patrizia Botta (coord.), Rumbos del hispanismo en el umbral del Cinquentenario de la AIH, Luigi Guarnieri Calò Caducci (ed.), Roma, Bagatto Libri, vol. VII, pp. 25-34.

Martín Romero, José Julio (2012b): "Biografía heroica y concepto de nobleza en Amadís de Gaula y otros libros de caballerías", La Corónica, 40/2, pp. 231-257.

Martín Romero, José Julio (2013): Una fábula moral de Alfonso de Palencia. La batalla campal de los perros contra los lobos, San Millán de la Cogolla, Cilengua.

Martín Romero, José Julio (2014): "Diego de Valera y su influencia en el Nobiliario vero de Hernán Mexía", en Cristina Moya García (ed.), Mosén Diego de Valera: entre las armas y las letras, Londres, Tamesis Books, pp. 151-177.

Martín Romero, José Julio (2015a): "El origen de la nobleza según el Nobiliario vero de Hernán Mexía", Bulletin of Spanish Studies, 92/1, pp. 1-23.

Martín Romero, José Julio (2015b): La guerra en la literatura castellana del siglo XV, Londres, Department of Iberian and Latin American Studies Queen Mary, Univ. of London.

Martín Romero, José Julio (2017): "Variantes de autor y estadios redaccionales del "Nobiliario vero" de Hernán Mexía", Revista de Literatura Medieval, 29, pp. 171-195.

Morales Borrero, Manuel (1997): Hernán Mexía, escritor giennense del siglo XV, Jaén, Diputación Provincial de Jaén/Instituto de Estudios Giennenses.

Palencia, Alfonso de (1996): De perfectione militaris triumphi. La perfeçión del triunfo, Javier Durán Barceló (ed.), Salamanca, Universidad de Salamanca.

Palencia, Alfonso de (1999): Gesta Hispaniensia ex annalibus svorvm diervm collecta, Brian Tate y Jeremy Lawrence (ed.), Madrid, Real Academia de la Historia.

Pulgar, Fernando del (2007): Crónica de los Reyes Católicos, Juan de Mata Carriazo (ed.), estudio preliminar de Gonzalo Pontón, Sevilla/Granada, Universidad de Sevilla/Editorial Universidad de Granada.

Riquer, Martín de (1967): Caballeros andantes españoles, Madrid, Espasa-Calpe.

Rodríguez Velasco, Jesús D. (1996): El debate sobre la caballería en el siglo XV: la tratadística caballeresca castellana en su marco europeo, Valladolid, Junta de Castilla y León.

Santillana, Marqués de (2003): Poesías completas, Maxim P. A. M. Kherkhof y Ángel Gómez Moreno (ed.), Madrid, Castalia.

Torre, Alfonso de la (1991): Visión deleytable, Jorge García López (ed.), Salamanca, Universidad de Salamanca. 
Valera, Diego de (1959a): Espejo de verdadera nobleza, en Mario Penna, Prosistas castellanos del siglo XV, Madrid, Atlas, pp. 89-116.

Valera, Diego de (1959b): Tratado de las armas, en Mario Penna, Prosistas castellannos del siglo XV, Madrid, Atlas, pp. 117-139.

Villena, Enrique de (2000a): "Traducción de la Divina Commedia", en Obras completas, Pedro M. Cátedra (ed.), Madrid, Fundación José Antonio de Castro, vol. 3, pp. 515-1039.

Villena, Enrique de (2000b): "Traducción y glosas de la Eneida, libros IV-XII", en Obras completas, Pedro M. Cátedra (ed.), Madrid, Fundación José Antonio de Castro, vol. 3, pp. 1-513.

Weiss, Julian (1992): "La Qüistión entre dos cavalleros: Un nuevo tratado político del siglo XV", Revista de Literatura Medieval, IV, pp. 9-39.

Fecha de recepción: 14 de junio de 2016

Fecha de aceptación: 28 de octubre de 2016 